\title{
Management of Retroperitoneal Liposarcoma: A Case Report
}

\author{
Joseph Yorke1,2, Pius Agbenorku1,3*, Roland Awoonor-Williams', Michael Offoe Adinku4, \\ Eseenam Anita Agbeko4, Joseph Yaw Manu', Kodwo Aboagye Addae4, \\ Papa Kwesi Sonsomir Fiifi Yankson", Dorcas Ahulu², Daniel Anning Gyawus, \\ Nana Esi Abeduwa Abaidoo5, Dennis Afful-Yorkee ${ }^{5}$ \\ ${ }^{1}$ Department of Surgery, School of Medical Sciences, College of Health Sciences, Kwame Nkrumah University of \\ Science and Technology, Kumasi, Ghana \\ ${ }^{2}$ Directorate of Anaesthesia and Intensive Care, Komfo Anokye Teaching Hospital, Kumasi, Ghana \\ ${ }^{3}$ Reconstructive Plastic Surgery \& Burns Unit, Department of Surgery, School of Medical Sciences, College of \\ Health Sciences, Kwame Nkrumah University of Science and Technology, Kumasi, Ghana \\ ${ }^{4}$ General Surgery Unit, Directorate of Surgery, Komfo Anokye Teaching Hospital, Kumasi, Ghana \\ ${ }^{5}$ School of Medical Sciences, College of Health Sciences, Kwame Nkrumah University of Science and \\ Technology, Kumasi, Ghana \\ Email: :pimagben@yahoo.com
}

Received 29 June 2016; accepted 20 August 2016; published 23 August 2016

Copyright (C) 2016 by authors and Scientific Research Publishing Inc.

This work is licensed under the Creative Commons Attribution International License (CC BY).

http://creativecommons.org/licenses/by/4.0/

cc) (i)

Open Access

\begin{abstract}
Retroperitoneal liposarcoma is a rare malignant tumour with an incidence of 2.5 per million people annually. It is the most common type of all the retroperitoneal malignant tumours. Early diagnosis of the tumour is difficult because of absence of specific clinical presentation. Symptoms would only occur if the tumour exhibits pressure on the surrounding organs. It usually occurs between the fourth to sixth decades of life affecting both genders equally. Histological subtypes include: well-differentiated, poorly differentiated, myxoid, round cell and pleomorphic. Radiological imaging useful in diagnosis include: ultrasonography, computed tomography and magnetic resonance imaging. Complete surgical resection of the tumour and the adjacent viscera involved or organs remained the mainstay of treatment. Radiotherapy plays a role in reducing the risk of recurrence but its effect on the overall survival of patients is not known. The case presented is a 48-year-old male patient with retroperitoneal liposarcoma, treated by complete surgical resection of the tumour and right hemicolectomy and currently on follow-up for possible recurrence.
\end{abstract}

\section{Keywords}

Retroperitoneal, Liposarcoma, Surgical Resection, Malignant, Tumour

\footnotetext{
"Corresponding author.
}

How to cite this paper: Yorke, J., Agbenorku, P., Awoonor-Williams, R., Adinku, M.O., Agbeko, E.A., Manu, J.Y., Aboagye Addae, K., Fiifi Yankson, P.K.S., Ahulu, D., Anning Gyawu, D., Abaidoo, N.E.A. and Afful-Yorke, D. (2016) Management of Retroperitoneal Liposarcoma: A Case Report. Surgical Science, 7, 361-367. http://dx.doi.org/10.4236/ss.2016.78052 


\section{Introduction}

Liposarcoma is a common type of soft tissue sarcoma [1], which occurs most commonly in the extremities (52\%), followed by the retroperitoneal space (19\%) [2]. Liposarcoma can be histologically subdivided into five subtypes: well-differentiated, myxoid, round cell, pleomorphic and poorly differentiated [3]. Generally, round cell, pleomorphic and poorly differentiated subtypes are regarded as high-grade; whilst well-differentiated and myxoid liposarcoma are low-grade. Its occurrence within the retroperitoneal space is the focus in the index case. Retroperitoneal liposarcoma is the most frequently observed subtype of retroperitoneal tumour, with an incidence of 2.5 per million people annually [4]. It usually occurs between 40 - 60 years of age, and affects the genders equally [1] [5]. Its occurrence within the retroperitoneal space is usually asymptomatic until the tumour is large enough to compress the surrounding organs [6]. The large space of the retroperitoneum permits the tumour to grow to a large size before exhibiting symptoms of compression or infiltration. These include abdominal distension, abdominal pain, gastrointestinal haemorrhage, early satiety, vomiting and weight loss. Nerve root compressive symptoms such as paraesthesia and paresis have also been reported. The paucity of specific symptoms and signs to aid clinical diagnosis shifts the focus to radiological investigations as the key in unravelling the possible diagnosis.

Radiological imaging provides important information with regards to the position, size and involvement or otherwise of surrounding structures especially major vessels as well as lymph nodes and distant metastasis. To aid treatment, the tumour must be staged comprehensively. Various criteria are available for staging. However, the American joint commission on cancer staging provides an in-depth staging which is of great prognostic value [7]. The mainstay of treatment involves complete resection of the tumour and any involved adjacent organs. Radiotherapy as an adjunct either pre-operatively or post operatively reduces the risk of local recurrence but has not been shown to have an effect on survival. Its use being limited is based on the location of the tumour in the body. In contrast to radiotherapy, the role of chemotherapy is not clear [7]. Even with complete removal of the liposarcoma, prognosis remains variable. The 5-year survival rate of well-differentiated retroperitoneal liposarcoma is $83 \%$ and $20 \%$ for the poorly differentiated subtype [8].

\section{Case Report}

A 48 year-old male was seen at the Surgical Out-Patient Clinic of the Komfo Anokye Teaching Hospital, Kumasi, Ghana, following a referral from a private facility in Kumasi. His presenting complaint was abdominal distension for about 2 years associated with weight loss. History of abdominal pain, early satiety, jaundice, vomiting, fever, drenching night sweats, weight loss, dyspnoea and pedal swelling were all negative. The past medical and surgical histories of the patient were unremarkable. In his social history he had been the topic for discussion in their community because of the size of his abdomen and that had led to the family breaking apart. The physical examination revealed a middle aged man who was not pale, anicteric and not wasted with lymphadenopathy. He was haemodynamically stable. Examination of the chest was unremarkable. The abdomen was grossly distended with a palpable mass comparable to that of a 40 week gestational uterus (Figures 1-3). The liver, spleen and kidneys were not palpable. Shifting dullness and fluid thrill were both negative. All the laboratory parameters (full blood count, urea, creatinine, electrolytes, CA 19-9, CA 72-4, CEA, AFP) were within normal ranges. An abdominal ultrasonography done demonstrated a complex lobulated relatively well defined mass of size $29 \mathrm{~cm}$ by $14.6 \mathrm{~cm}$ extending from the epigastrium through the umbilical region to the pelvis which was poorly vascularised. Origin of the mass was likely mesenteric with liver involvement. Computed Tomography (CT) to assess the mass could not be done because the patient could not afford it.

In view of this limitation, an ultrasound guided biopsy was done and the specimen sent for histopathology. The results were indicative of mesenchymal Hamartoma originating from the liver.

The patient was counselled for resection of the tumour which he consented to. He was subsequently worked up for surgery.

Intra-operatively, it was determined that the mass, approximately $30 \mathrm{~cm}$ by $15 \mathrm{~cm}$ (Figure 4) originated from the right fatty paracolic capsule. The mesentery as well as the ascending colon was partly invaded. The right kidney and its capsule, liver, para aortic lymph nodes as well as the major abdominal vessels were not infiltrated.

En bloc resection of the tumour and right hemicolectomy was done. The specimen sent for histopathological analysis plus state of margins of resection. 


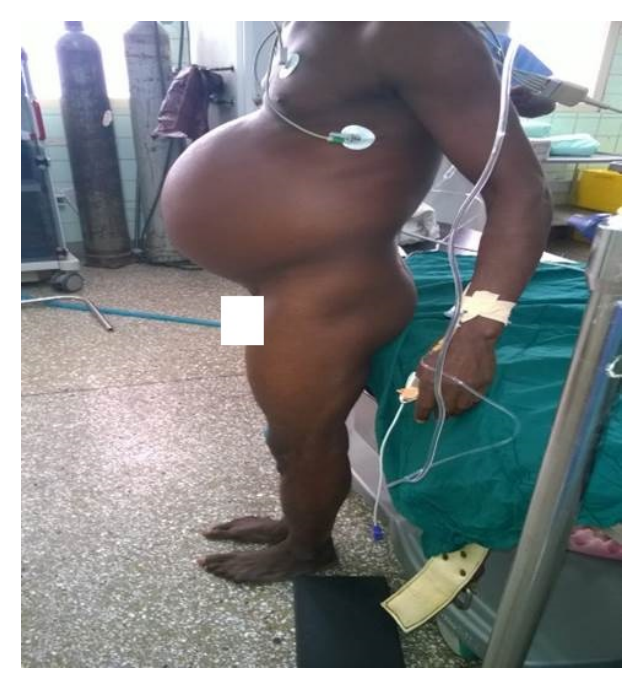

Figure 1. Photograph showing abdominal distension (lateral view).

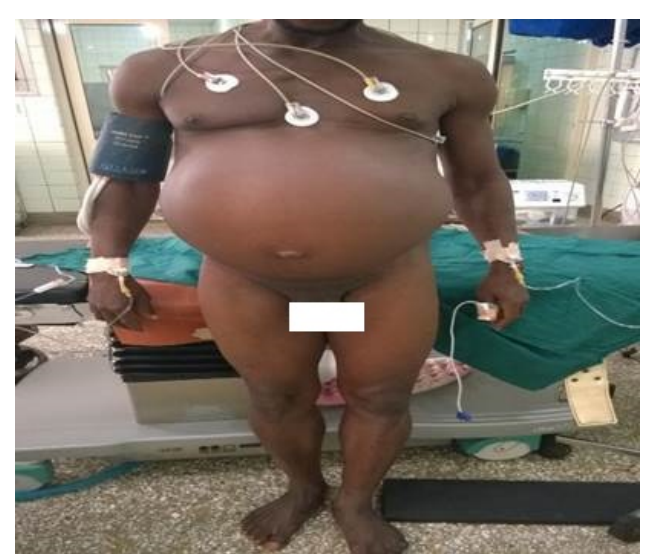

Figure 2. Photograph showing abdominal distension (anteroposterior view).

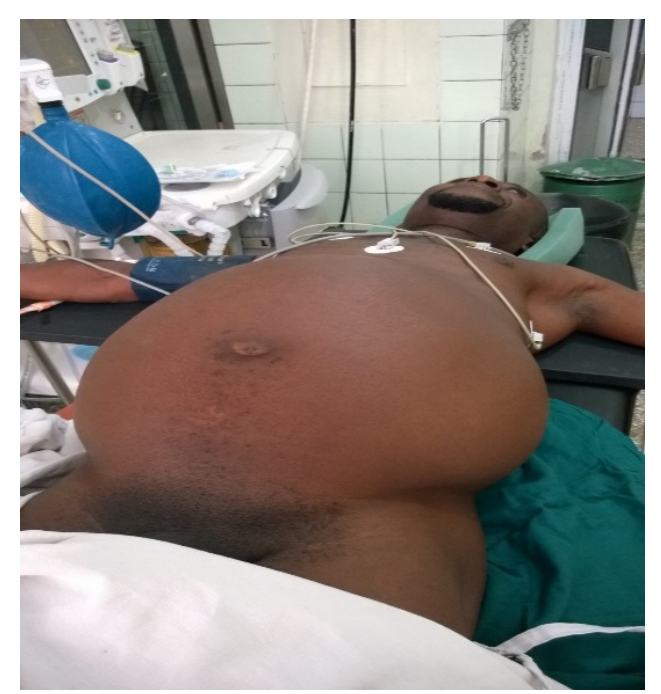

Figure 3. Photograph showing abdominal distension in supine view. 
The mass was pathologically identified as myxoid liposarcoma which was low grade (G1) with margins of resection being free of tumour. Lymph nodes examined had no evidence of metastasis. The pathological classification via TNM was assessed to be T2bN0M0. This was conducted at the Pathology Department of the Komfo Anokye Teaching Hospital, Kumasi, Ghana.

The tumour stage via the American joint commission on cancer staging was identified to be Stage 1B amenable to the above stated modality of treatment.

The patient recovered well and was discharged home a week after surgery (Figure 5 and Figure 6). He was scheduled for review and followed up on out-patient basis for the past 6 months. No recurrence has been observed yet.

\section{Discussion}

Retroperitoneal tumours predominantly originate from fat, loose connective tissue, fascia, muscles, lymphatic tissue or residual embryonic tissue, of which $80 \%$ are malignant. In the index case the tumour was identified to

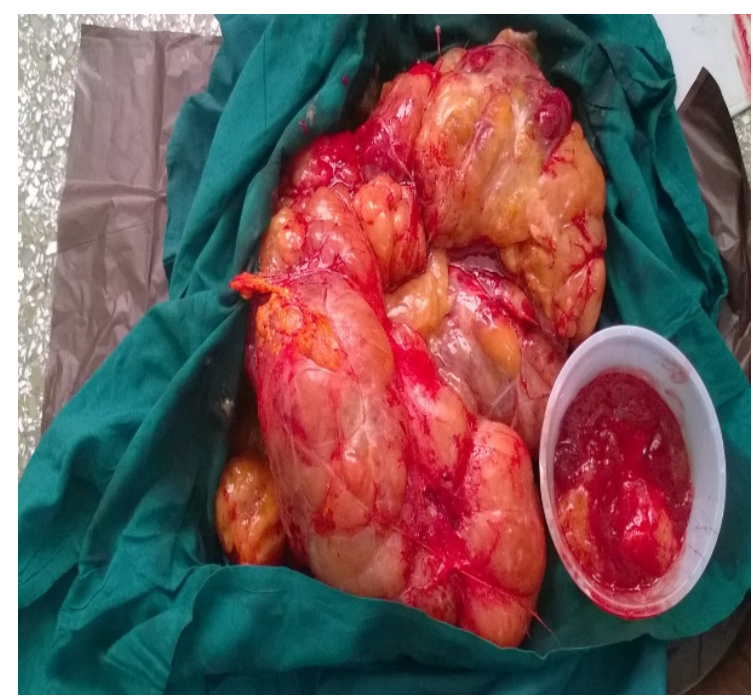

Figure 4. Photograph showing size of mass post excision.

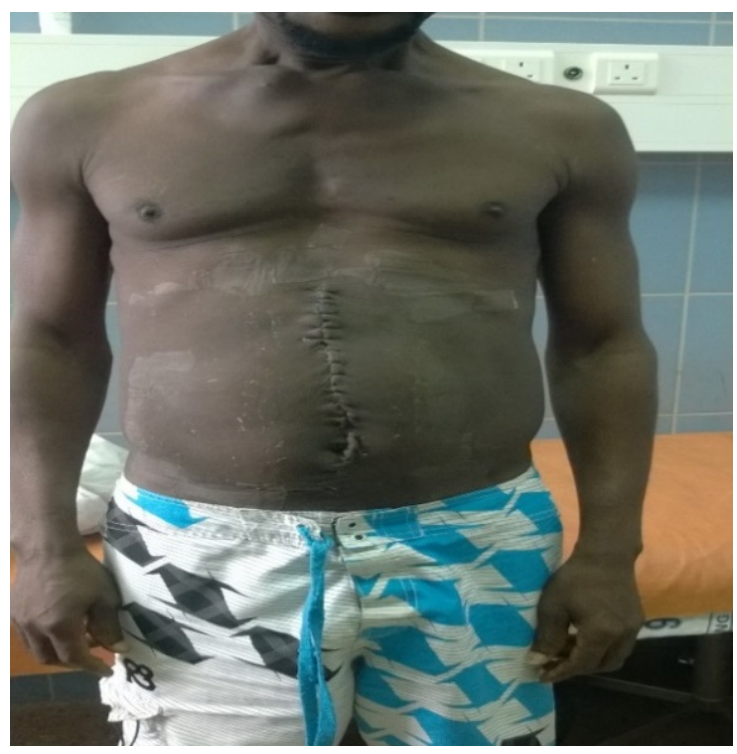

Figure 5. Photograph showing abdominal girth post excision (anteroposterior view). 


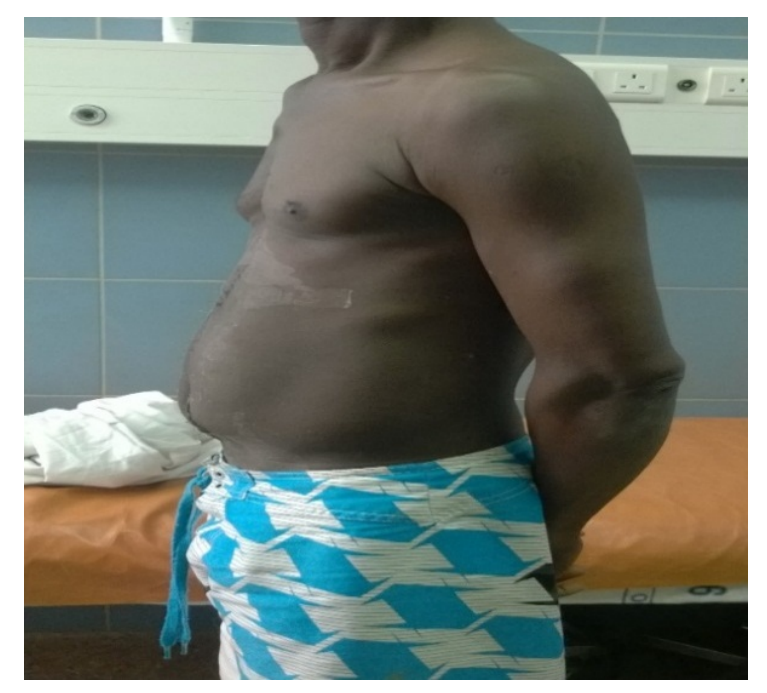

Figure 6. Photograph showing abdominal girth post excision (lateral view).

originate from the right fatty paracolic capsule.

The large volume of the retroperitoneal space allows tumour to grow without compressing the vital organs, resulting in rare early diagnosis. This is typified in the index case, where clinically the tumour was comparable with a forty week gestational uterus and immense size measured after resection of the tumour.

There is the exhibition of a very nonspecific symptom of abdominal distension which became bothersome months after onset. There were no compressive symptoms observed in this case which could have culminated in an earlier reporting to a health facility.

The immense limitation in diagnosis based on clinical examination brings to the fore the importance of radiological investigation. Even then, all modalities are helpful.

Computed tomography (CT) or magnetic resonance imaging (MRI) is better placed to give information on the tumour's location, size and involvement of adjacent structures.

On a CT scan, retroperitoneal liposarcoma usually appears as a large encapsulated mass containing variable amounts of fatty and soft tissue components [9]. MRI is important for the diagnosis of liposarcoma invasion of the abdominal aorta or inferior vena cava. Ultrasonography which is usually chosen for its convenience is of grave limitation in diagnosis when it comes to retroperitoneal tumours.

Its sensitivity and specificity is largely operator dependent. Its use in the case, displayed its limitation in determining the exact origin of the mass and involvement of adjacent structures. However, in the setting of financial constraints to the superior imaging modalities mentioned earlier on, it leaves room for very little options. The consequences are enormous; misdiagnosis as seen in this case. This led to an unwarranted need to biopsy the mass which is not generally recommended due to the probability of tumour seeding [10].

Staging the tumour is an integral part of the management. There are various staging systems available. The American joint commission on cancer staging used in this case provides an in-depth staging. This is of great prognostic value in determining the most effective modality of treatment.

The components of this comprehensive staging system include; size of the tumour, lymph node involvement or distant sites and histologic grade. The grade is determined post excision.

High histological grade is one of the most important negative prognostic factors in patients with retroperitoneal liposarcoma. CT and MRI are better placed to give majority of the components pre-operatively with the exception of the grade.

Our limitation in staging prior to surgery was as a result of limitation in undertaking advanced imaging. Post operatively, the staging was done and found to be stage $1 \mathrm{~B}$.

Effective treatment of retroperitoneal liposarcoma requires complete resection of the tumour and any adjacent viscera invaded by the tumour, commonly the kidney, followed by the colon [11]. In the index case complete resection was successful with clear margins.

It is worth noting that high grade tumours have high recurrence rates due to tumour biology, challenges in en 
bloc resection and limitation in the use of high dose radiation therapy on visceral organs [12]-[15]. Radiotherapy is limited to extremity liposarcoma to reduce the risk of recurrence.

In view of these factors the goal of achieving clear margins cannot be overemphasized. Clear margins were achieved in this case. There is no evidence that chemotherapy or radiotherapy improve survival rates [16].

Even with complete removal of the liposarcoma, prognosis is variable. The 5-year survival rate of welldifferentiated retroperitoneal liposarcoma is $83 \%$ and $20 \%$ for the poorly differentiated tumour subtype. Welldifferentiated liposarcomas may recur locally, but the metastatic potential is low, while pleomorphic liposarcomas have high metastatic potential, which may reduce the survival rate [17].

Keen follow up of patients is needed to assess the survival rate and recurrence rate in our part of the world. The patient is on regular follow up. It also requires enlisting all patients with this condition to have larger database.

It is worth noting that surgical resection is still favoured in those with advanced metastasis [18]-[20].

There is a keen follow up of the patient 6 months post resection as stated initially for any local recurrence which remains the preliminary cause of mortality in retroperitoneal liposarcoma [21]. Interestingly, survival rate was found to improve in the patients who received a complete resection of their recurrent tumour compared with the patients who did not. It appears the gold standard of treatment remains to be removal of the local recurrence [22]. The anticipated challenges of the secondary operation in the event of recurrence should be borne in mind by the surgeon following the patient up in that the anatomical relationship would be more complex. The reason being that after the initial surgery, the anatomical position of structures may be altered and the tissues may adhere to one another or to important vessels.

However, this challenge is yet to be surmounted in the index case. The general recommendation in detecting recurrence requires the use of CT scan every 3 months for the first 2 years, every 6 months for 2 - 5 years and annually thereafter.

Significant limitation in this report is the inability of the patient to afford CT scan assessment pre-operatively as well as the follow up so far. This brings up the key questions of recurrence and misdiagnosis as stated earlier.

\section{Conclusion}

In conclusion, retroperitoneal liposarcoma is a rare disease with a high rate of recurrence. Complete resection of the tumour and involved adjacent organs is the benchmark of treatment. This is a reported case of giant retroperitoneal myxoid liposarcoma and puts it into context with previously reported cases.

\section{References}

[1] Mendenhall, W.M., Zlotecki, R.A., Hochwald, S.N., Hemming, A.W., Grobmyer, S.R. and Cance, W.G. (2005) Retroperitoneal Soft Tissue Sarcoma. Cancer, 104, 669-675. http://dx.doi.org/10.1002/cncr.21264

[2] Russell, W.O., Cohen, J., Enzinger, F., Hajdu, S.I., Heise, H., Martin, R.G., Meissner, W., Miller, W.T., Schmitz, R.L. and Suit, H.D. (1977) A Clinical and Pathological Staging System for Soft Tissue Sarcomas. Cancer, 40, 1562-157.

[3] Singer, S., Antonescu, C.R., Riedel, E. and Brennan, M.F. (2003) Histologic Subtype and Margin of Resection Predict Pattern of Recurrence and Survival for Retroperitoneal Liposarcoma. Annals of Surgery, 238, 358-371. http://dx.doi.org/10.1097/01.sla.0000086542.11899.38

[4] Neuhaus, S.J., Barry, P., Clark, M.A., Hayes, A.J., Fisher, C. and Thomas, J.M. (2005) Surgical Management of Primary and Recurrent Retroperitoneal Liposarcoma. British Journal of Surgery, 92, 246-252. http://dx.doi.org/10.1002/bjs.4802

[5] Mack, T.M. (1995) Sarcomas and Other Malignancies of Soft Tissue, Retroperitoneum, Peritoneum, Pleura, Heart, Mediastinum, and Spleen. Cancer, 75, 211-244. http://dx.doi.org/10.1002/1097-0142(19950101)75:1+<211::AID-CNCR2820751309>3.0.CO;2-X

[6] Bradley, J.C. and Caplan, R. (2002) Giant Retroperitoneal Sarcoma: A Case Report and Review of the Management of Retroperitoneal Sarcomas. The American Surgeon, 68, 52-56.

[7] Edge, S.B., Byrd, D.R., Compton, C.C., Eds. (2010) Soft Tissue Sarcoma. In: AJCC Cancer Staging Manual. 7th Edition, Springer, New York, 291-298.

[8] Fabre-Guillevin, E., Coindre, J.M., Somerhausen, N.S., Bonichon, F., Stoeckle, E. and Bui, N.B. (2006) Retroperitoneal Liposarcomas: Follow-Up Analysis of Dedifferentiation after Clinicopathologic Reexamination of 86 Liposarcomas and Malignant Fibrous Histiocytomas. Cancer, 106, 2725-2733. http://dx.doi.org/10.1002/cncr.21933 
[9] Chang, I.Y. and Herts, B.R. (2013) Retroperitoneal Liposarcoma. The Journal of Urology, 189, 1093-1094. http://dx.doi.org/10.1016/j.juro.2012.11.122

[10] Clark, M.A. and Thomas, J.M. (2003) Portsite Recurrence after Laparoscopy for Staging of Retroperitoneal Sarcoma. Surgical Laparoscopy, Endoscopy \& Percutaneous Techniques, 13, 290-291. http://dx.doi.org/10.1097/00129689-200308000-00015

[11] Chen, Z.H. and Song, X.M. (2009) The Therapeutic Progress in Retroperitoneal Liposarcoma. Chin J Gen Surg, 24, 81-83. (In Chinese)

[12] Zhai, H.X., Ma, X.M. and Jia, Q.Q. (2010) A Case Report of Giant Retroperitoneal Liposarcoma. Chin Community Doct, 12, 167-168. (In Chinese)

[13] Zhuang, G.Y., Dong, C.W., Li. J.Q. and Li, M.J. (2009) Multiple Retroperitoneal Dedifferentiated Liposarcoma: A Case Report. Chin J Curr Adv Gen Surg, 12, 89-90. (In Chinese)

[14] Liu, B., Wang, Q.F., Yu, J.H., Wang, D.G., Zhang, Y. and Xu, Y.C. (2013) Giant Abdominal Liposarcoma: A Case Report. Chin J Gerontol, 33, 452. (In Chinese)

[15] Liu, C.L. and Zhang, H.Y. (2008) Multiple Retroperitoneal and Abdominal Liposarcoma: A Case Report. Chin J Gen Surg, 23, 320. (In Chinese)

[16] Perez, E.A., Gutierrez, J.C., Moffat Jr., F.L., et al. (2007) Retroperitoneal and Truncal Sarcomas: Prognosis Depends upon Type Not Location. Annals of Surgical Oncology, 14, 1114-1122. http://dx.doi.org/10.1245/s10434-006-9255-X

[17] Nijhuis, P.H., Sars, P.R., Plaat, B.E., Molenaar, W.M., Sluiter, W.J. and Hoekstra, H.J. (2000) Clinico-Pathological Data and Prognostic Factors in Completely Resected AJCC Stage I-III Liposarcomas. Annals of Surgical Oncology, 7, 535-543. http://dx.doi.org/10.1007/s10434-000-0535-6

[18] Chen, R.F. and Peng, D.T. (2007) Giant Retroperitoneal Liposarcoma: A Case Report. Chin J Dig Surg, 6, 380. (In Chinese)

[19] Liu, C.Z., Xin, H., Li, G.D. and Wang, L.L. (2013) Giant Retroperitoneal Liposarcoma: A Case Report. Jilin Medical Journal, 34, 5535-5536. (In Chinese)

[20] Shen, Y., He, X.J., Li, Y., Lv, R.G. and Li, P. (2009) Giant Retroperitoneal Liposarcoma: A Case Report. The Journal of Practical Medicine, 25, 516. (In Chinese)

[21] Milone, M., Pezzullo, L.S., Salvatore, G., Pezzullo, M.G., Leongito, M., Esposito, I. and Milone, F. (2011) Management of High-Grade Retroperitoneal Liposarcomas: Personal Experience. Updates in Surgery, 63, 119-124. http://dx.doi.org/10.1007/s13304-011-0061-z

[22] Bautista, N., Su, W., and O’Connell, T.X. (2000) Retroperitoneal Soft-Tissue Sarcomas: Prognosis and Treatment of Primary and Recurrent Disease. The American Surgeon, 66, 832-836.

\section{Submit or recommend next manuscript to SCIRP and we will provide best service for you:}

Accepting pre-submission inquiries through Email, Facebook, LinkedIn, Twitter, etc.

A wide selection of journals (inclusive of 9 subjects, more than 200 journals)

Providing 24-hour high-quality service

User-friendly online submission system

Fair and swift peer-review system

Efficient typesetting and proofreading procedure

Display of the result of downloads and visits, as well as the number of cited articles

Maximum dissemination of your research work

Submit your manuscript at: http://papersubmission.scirp.org/ 